\title{
RESEARCH
}

Open Access

\section{Perception of quality of life by children and adolescents with cleft lip/palate after orthodontic and surgical treatment: gender and age analysis}

Ana Ruiz-Guillén ${ }^{1,2}$, Carlos Suso-Ribera ${ }^{3}$, Martín Romero-Maroto ${ }^{1,4}$, Carmen Gallardo ${ }^{5}$ and Cecilia Peñacoba ${ }^{6^{*}}$ (D)

\begin{abstract}
Background: The quality of life (QoL) of children and adolescents with cleft lip/palate (CL/P) has been shown to be a predictor of good psychosocial functioning in this population group. This study aimed to measure QoL, from the patient's perception of change produced by the different surgical and orthodontic treatments carried out since early childhood, and if gender and age are modulating the outcome variables results.

Materials and methods: A cross-sectional research study was carried out. The study included 60 patients with cleft lip, cleft palate, or cleft lip/palate, aged between 8 and 18, who were in orthodontic treatment and had undergone at least one surgery. They were asked to complete the Quality-of-Life Adolescent Cleft Questionnaire (QoLAdoCleft), which allows the assessment of the QoL through self-perception of improvement after surgical and orthodontic interventions. In particular, this questionnaire (administered only once), allows the evaluation of self-perception of QoL at the present time and before orthodontic and surgical treatment. This double assessment was carried out for the domains of physical, psychological, and social health. The results were analysed by looking at the interaction of gender and age.

Results: Statistically significant differences were found in the perception of the current QoL in comparison to the retrospective perception in all the dimensions considered. The perception of QoL improved in all cases. The results also showed a moderation of gender in the relation between perception of previous behaviour and social function and actual behaviour and social function.

Conclusion: The results indicated that patients perceived their quality of life had improved as a result of the treatments received, with the highest effect sizes found in the physical health domain. Specifically, the improvement in QoL in behaviour and social function tended to be influenced to a greater extent by perception of previous QoL. In this sense, personalized preventative measures from holistic and biopsychosocial approaches are necessary.
\end{abstract}

Keywords: Quality of life, Cleft lip and/or palate, Children, Adolescents

\footnotetext{
* Correspondence: cecilia.penacoba@urjc.es

${ }^{6}$ Deparment of Psychology, Rey Juan Carlos University, Madrid, Spain

Full list of author information is available at the end of the article
}

\section{Springer Open}

(c) The Author(s). 2021 Open Access This article is licensed under a Creative Commons Attribution 4.0 International License, which permits use, sharing, adaptation, distribution and reproduction in any medium or format, as long as you give appropriate credit to the original author(s) and the source, provide a link to the Creative Commons licence, and indicate if changes were made. The images or other third party material in this article are included in the article's Creative Commons licence, unless indicated otherwise in a credit line to the material. If material is not included in the article's Creative Commons licence and your intended use is not permitted by statutory regulation or exceeds the permitted use, you will need to obtain permission directly from the copyright holder. To view a copy of this licence, visit http://creativecommons.org/licenses/by/4.0/. 


\section{Introduction}

Cleft lip/palate $(\mathrm{CL} / \mathrm{P})$ is a congenital anomaly that leads to problems with facial appearance and function (e.g. chewing, swallowing, hearing, and speech) [1-4]. Facial malformations and the conditions of their treatment, which are considered as stress factors, can have potentially significant consequences for the lives of these patients [5]. Physical attractiveness is an important psychological variable in the field of appearance, which influences child development [6]. For this reason, children and adolescents with $\mathrm{CL} / \mathrm{P}$ can be a particularly vulnerable group [2].

The study of oral health-related quality of life (OHRQoL) is the most used in the field of $\mathrm{CL} / \mathrm{P}$, constituting an indicator of success of medical interventions [3, 4]. Information on OHRQoL helps rehabilitation specialists understand the burden of disease from the patient's perspective and thus improve treatment recommendations [7].

Treatment of CL/P affects many domains related to a patient's QoL, including appearance, speech, self-image, social integration, and physical and psychological functioning [8].

The treatment of CL/P patients leads to an improvement in their emotional states related to body image, and it also increases self-esteem, self-confidence, and social competence, all of which have positive effects on increasing QoL $[1,6,9]$. For this reason, the treatment is focused on achieving excellent functional, but also aesthetic, results that improve the QoL of patients with CL/P [8].

Treatment protocols include numerous surgical and orthodontic treatments from birth until adulthood [10]. The first phase of the treatment lies in placing presurgical infant orthopedics such as Nasoalveolar Molding or Latham-Millard [11, 12], or lip adhesion through the use of adhesive strips [13], these treatments improve surgical outcomes as they facilitate tension-free closure of the lip, improved nasal symmetry, and allow potential soft tissue surgical unification of the alveolar segments through a gingivoperiosteoplasty at approximately 3 months of age [12]. In cases of a cleft palate, at about 912 months of age, palatoplasty is performed [14]. Depending on the degree of malocclusion, these patients need orthodontic palatal expansion and/or maxillary protraction [15], combined with bone grafting for the closure of the oronasal communication, in which case several grafts may be necessary $[13,16]$. Treatment continues with a fixed orthodontics appliance (brackets) [17]; in some cases, it is necessary to perform a surgical treatment the Le Fort 1 and sagittal osteotomy of the mandible [13].

Taking into account studies that have demonstrated the impact that treatment has on the individual $[1,2,5,18,19]$, a multidisciplinary approach is necessary, as patients' mental state, their expectations regarding the treatment, and the effects of the treatment on their well-being need to be considered [5]. In this context, there are studies that assess the QoL of children and adolescents with CL/P using specific instruments for this pathology, such as the Autoquestionnaire Qualitée de Vie Enfant Image [20], CLEFT-Q [21]' or THAICLEFT QoL Questionnaire [22]; however, these instruments are usually used to measure this variable at a single moment in time, with 'pre-post' designs being less common. Although studies that measure this variable before and after treatment (at two time points) can also be found, such as the study carried out by Beluci and Genaro (2016) [1] and Antoun et al. (2015) [23], the instruments used are not specific for patients with a cleft.

An interesting approach in this sense is that proposed by Piombino et al. [24] through their questionnaire Quality of Life Adolescent Cleft Questionnaire (QoLAdoCleft). This questionnaire allows an assessment (at a single point in time) of the current QoL of the patient, together with a retrospective perception of their pretreatment QoL, therefore providing information on the patient's perception of improved QoL treatment.

Thus, the aim of the current cross-sectional study has been to assess both the perception of current and retrospective QoL before treatment among children and adolescents with $\mathrm{CL} / \mathrm{P}$, taking into account functional, aesthetic, psychological, and social dimensions. Additionally, the study aimed to examine whether gender and age influence the results.

\section{Methods}

\section{Sample characteristics}

We recruited 60 children and adolescents with $\mathrm{CL} / \mathrm{P}$ $\left(M_{\text {age }}=12.80\right.$ years; $\mathrm{SD}=2.79 ;$ age range $=8-18$ years; 27 males and 33 females) who were attending orthodontic treatment in two private health centres in Madrid. Specifically, participation by age was as follows: 8 years $(n=2 ; 3.3 \%), 9$ years $(n=4 ; 6.7 \%), 10$ years $(n=11$; $18.3 \%), 11$ years $(n=6 ; 10 \%), 12$ years $(n=9 ; 15 \%), 13$ years $(n=5 ; 8.3 \%), 14$ years $(n=3 ; 5 \%), 15$ and 16 years ( $n=7 ; 11.7 \%$ respectively), 17 years $(n=5 ; 8.3 \%)$, and 18 years $(n=1 ; 1.7 \%)$.

Approximately $17 \%(n=10)$ had a diagnosis of isolated cleft lip, 23.3\% $(n=14)$ had isolated cleft palate, and $60 \%(n=36)$ had CL/P. Ninety per cent $(n=54)$ had undergone more than one surgery. The mean age at which they underwent the first surgery was 5.83 months $(\mathrm{SD}=3.97)$, and 36.07 months $(\mathrm{SD}=37.69)$ for those who underwent a second surgery.

All patients were undergoing orthodontic treatment. According to the treatment protocol for patients with a cleft, thirty-three patients in the sample (55\%), who were in mixed dentition, were being treated with a Hyrax 
expander, twenty of these also needed a face mask for early treatment of Class III malocclusion. Twenty-seven patients (45\%) were in treatment with fixed braces. If the malocclusion was not solved with orthodontic treatment, these cases would have to be prepared for orthognathic surgery. The treatment duration varied among patients, depending on the severity of the malocclusion.

Since most were in the middle of orthodontic and/or surgical treatment, post-occlusal outcome was not included as a variable in this study.

\section{Eligibility criteria}

The inclusion criteria for the sample were to be between 8-18 years old, in orthodontic treatment and to have undergone previous surgery to improve their appearance and/or functionality. Patients with a syndromeassociated cleft that could interfere with their intellectual or cognitive ability were excluded.

The sample age was chosen so that the patients were already in mixed dentition, and also had an appropriate level of understanding to answer the questionnaire. Moreover, at the age of 8 , social relations become more important and can influence QoL [23]. Although the questionnaire has been previously validated (by our research team) for patients aged 8-18, children were assisted by a researcher who made sure they understood the answer format, without influencing the children answers.

During the sampling period, 75 patients met the inclusion criteria; however, sixty $(80 \%)$ completed the selfreport questionnaire in full. The reason for noncompletion was that parents, or the patients themselves, did not consider that they had any psychological adjustment problem.

\section{Data collection}

Data was obtained through self-reported questionnaires that patients filled out during their orthodontic checkups. The study was conducted from 2016 to 2018.

Participants self-reported their gender and age at the time the questionnaires were collected. The convenience sample consisted of 60 consecutive patients, from two geographical areas of two health centres, specialized in the treatment of cleft.

The study followed the guidelines of the research ethics committee of the Rey Juan Carlos University. No. 110720166716 , and informed consent was obtained from the patients' parents.

\section{Measures}

\section{Quality of life}

The Spanish adaptation of the Quality-of-Life Adolescents Cleft Questionnaire (QoLAdoCleft) was used [24]. Specifically, the QoLAdoCleft allows for both the assessment of current QoL and the retrospective perception of it before treatment in three domains: physical, psychological, and social health. In terms of physical health, the dimensions of physical function were measured (4 items: chewing, regurgitation, associated ear, and breathing pathologies; Cronbach's alpha $=.75$ ), communication (2 items: pronunciation, understanding by others; Cronbach's alpha $=.80)$, and pain $(1$ item: existence of triggers points). For psychological health, the domains of self-concept (2 items: feeling less valid or different from others, Cronbach's alpha $=.87$ ) and behaviour ( 1 item: tendency to isolate) were measured. For social health, the social function domain was measured (1 item: influence of physical appearance on social activities). These items were intended to evaluate the patient's condition before and after orthodontic and surgical treatment, although the questionnaire was administered only after physical and/or functional improvement of the orthodontic and surgical treatment in all cases.

Due to the wide range of ages covered in this study, the level of improvement differed between patients because they were at different stages of treatment, and the information obtained was based on subjective assessment of the health status of the individual.

\section{Data analysis}

First, perception of improvement of QoL due to treatment was analysed using a Student's $t$-test for related samples. Second, moderation analyses were conducted with model 1 from the PROCESS Macro version 3.4 [25]. Age and gender were used as moderators, QoL dimensions before treatment as independent variables, and QoL dimensions after treatment as the outcomes. Twelve models were tested (six for gender and six for age as moderators), two for each QoL dimension. Statistical significance was set at an alpha level of 0.05. In the PROCESS Macro, for the continuous variable (i.e. age), the recommended values in conditional tables and graphical representations are the 16th, 50th, and 84th percentiles. Thus, these cut-offs were used to calculate conditional effects (i.e. effects of an independent variable on an outcome for different values of a moderator) in the case of a significant moderation effect.

\section{Results}

Perception of improvement of QoL due to treatment

As can be seen in Table 1, all QoL dimensions assessed showed statistically significant differences. QoL was perceived to have improved after treatment in all cases. In terms of the effect size, the highest improvements were observed for the physical function and communication dimensions, whereas pain showed small effect sizes. Improvements in psychological and social health showed moderate effect sizes. 
Table 1 Perception of improvement in the QoL dimensions after orthodontic and surgical treatment

\begin{tabular}{|c|c|c|c|c|c|}
\hline & $\begin{array}{l}\text { Before } \\
\text { Mean (SD) }\end{array}$ & $\begin{array}{l}\text { After } \\
\text { Mean (SD) }\end{array}$ & $t$ & $p$ & $d$-Cohen \\
\hline \multicolumn{6}{|l|}{ Physical health } \\
\hline Physical function & $6.63(4.01)$ & $3.20(2.44)$ & 8.083 & $<.000$ & 1.03 \\
\hline Communication & $3.85(2.50)$ & $2.03(1.86)$ & 6.850 & $<.000$ & .82 \\
\hline Pain & $.61(.85)$ & $.34(.71)$ & 2.519 & .015 & .34 \\
\hline \multicolumn{6}{|l|}{ Psychological health } \\
\hline Self-concept & $3.02(2.60)$ & $2.03(2.08)$ & 4.448 & $<.000$ & .42 \\
\hline Behaviour & $1.16(1.31)$ & $.70(.99)$ & 3.746 & $<.000$ & .40 \\
\hline \multicolumn{6}{|l|}{ Social health } \\
\hline Social function & $1.13(1.15)$ & $.60(.90)$ & 4.361 & $<.000$ & .51 \\
\hline
\end{tabular}

\section{Regression and moderation analyses with gender as moderator}

The results of the regression analyses, including the analysis of moderation effects (gender), are presented in Table 2. The prediction of QoL dimensions after treatment from their respective QoL dimensions before treatment, gender, and their interaction demonstrated significant direct contributions of each dimension before treatment on their respective dimension after treatment. However, we found no direct effect of gender on QoL dimensions after treatment. The results showed a moderation of gender in the relation between behaviour before treatment and behaviour after treatment (beta = $0.31, t=-2.28, p=.02,95 \%$ confidence interval $[\mathrm{CI}]:-$ $0.59,-0.04$ ) and between social function before treatment and social function after treatment (beta $=-0.33$, $t=-2.09, p=.04,95 \%$ CI: $-0.64,-0.01)$.

As noted earlier, post hoc analyses were planned to examine significant moderations in more depth. Table 3 and Fig. 1 show the results for the moderation of gender in the relation between behaviour before treatment and behaviour after treatment, whereas Table 4 and Fig. 2 give those for the moderation of gender in the relation between social function before treatment and social function after treatment. As noted, behaviour and social function before treatment had a higher predictive capacity for behaviour and social function after treatment for girls than boys.

Table 2 Prediction of quality of life after orthodontic and surgical treatment from quality of life before treatment, gender, and their interaction

\begin{tabular}{|c|c|c|c|c|c|c|c|}
\hline & $R^{2}$ & $F$ & $p$ & Beta & $t$ & $p$ & $95 \% \mathrm{Cl}$ \\
\hline DV $=$ Physical function & 0.36 & 10.36 & $<.000$ & & & & \\
\hline Physical function (before) & & & & 0.38 & 4.46 & $<.000$ & $0.21,0.56$ \\
\hline Gender & & & & -0.75 & -1.44 & .15 & $-1.80,0.29$ \\
\hline Interaction & & & & -0.06 & -0.47 & .63 & $-0.33,0.2$ \\
\hline DV $=$ Communication & 0.36 & 10.54 & $<.000$ & & & & \\
\hline Communication (before) & & & & 0.40 & 3.67 & $<.000$ & $0.18,0.62$ \\
\hline Gender & & & & -0.26 & -0.66 & .51 & $-1.07,0.54$ \\
\hline Interaction & & & & 0.09 & 0.61 & .54 & $-0.22,0.41$ \\
\hline DV $=$ Pain & 0.22 & 5.19 & .003 & & & & \\
\hline Pain (before) & & & & 0.46 & 3.24 & .002 & $0.18,0.75$ \\
\hline Gender & & & & -0.15 & -0.87 & .39 & $-0.50,0.19$ \\
\hline Interaction & & & & -0.13 & -0.66 & .51 & $-0.55,0.27$ \\
\hline DV $=$ Self-concept & 0.57 & 25.04 & $<.000$ & & & & \\
\hline Self-concept (before) & & & & 0.62 & 7.38 & $<.000$ & $0.45,0.79$ \\
\hline Gender & & & & -0.10 & -0.28 & .78 & $-0.84,0.64$ \\
\hline Interaction & & & & -0.08 & -0.52 & .60 & $-0.39,0.23$ \\
\hline DV = Behaviour & 0.54 & 21.66 & $<.000$ & & & & \\
\hline Behaviour (before) & & & & 0.68 & 7.06 & $<.000$ & $0.49,0.88$ \\
\hline Gender & & & & -0.31 & -1.74 & .08 & $-0.68,0.05$ \\
\hline Interaction & & & & -0.31 & -2.28 & .02 & $-0.59,-0.04$ \\
\hline DV $=$ Social function & 0.44 & 14.59 & $<.000$ & & & & \\
\hline Social function (before) & & & & 0.63 & 5.89 & $<.000$ & $0.41,0.84$ \\
\hline Gender & & & & -0.32 & -1.79 & .08 & $-0.69,0.04$ \\
\hline Interaction & & & & -0.33 & -2.09 & .04 & $-0.64,-0.01$ \\
\hline
\end{tabular}


Table 3 Conditional effects of behaviour before orthodontic and surgical treatment on behaviour after treatment depend on gender

\begin{tabular}{lllll}
\hline Gender & Beta (social function before) & $\boldsymbol{t}$ & $\boldsymbol{p}$ & $\mathbf{9 5 \% ~ C l}$ \\
\hline Girls & 0.683 & 7.066 & $<.000$ & $0.49,0.88$ \\
Boys & 0.368 & 3.723 & $<.000$ & $0.17,0.57$ \\
\hline
\end{tabular}

\section{Regression and moderation analyses with age as} moderator

The prediction of QoL dimensions after treatment from their respective QoL dimensions before treatment, age, and their interaction revealed significant direct contributions from each of the dimensions before treatment on their respective dimension after treatment. No moderation effect of age on QoL dimensions after treatment was observed. The results showed a direct effect of age on social function after treatment (beta $=-0.10, t=-$ 3.23, $p=.002,95 \% \mathrm{CI}:-0.17,-0.04)$, indicating that older patients reported better social function after treatment.
Table 4 Conditional effects of social function before orthodontic and surgical treatment on social function after treatment depend on gender

\begin{tabular}{lllll}
\hline Gender & Beta (behaviour before) & $\boldsymbol{t}$ & $\boldsymbol{p}$ & $\mathbf{9 5 \% ~ C l}$ \\
\hline Girls & 0.627 & 5.891 & $<.000$ & $0.41,0.84$ \\
Boys & 0.299 & 2.576 & .012 & $0.06,0.53$ \\
\hline
\end{tabular}

\section{Discussion}

The main objective of this study was to analyse whether QoL increases in children and adolescents with CL/P after their aesthetics and functionality have been treated with orthodontics and surgery. The results showed that patients perceive that their current QoL has increased after orthodontic and surgical treatment, in relation to all the evaluated domains (physical, psychological, and social health). The largest effect sizes were found in physical health, specifically in physical function and communication.

Although these results are generally consistent with those found in the literature, it is difficult to make specific comparisons by dimension, given the heterogeneity

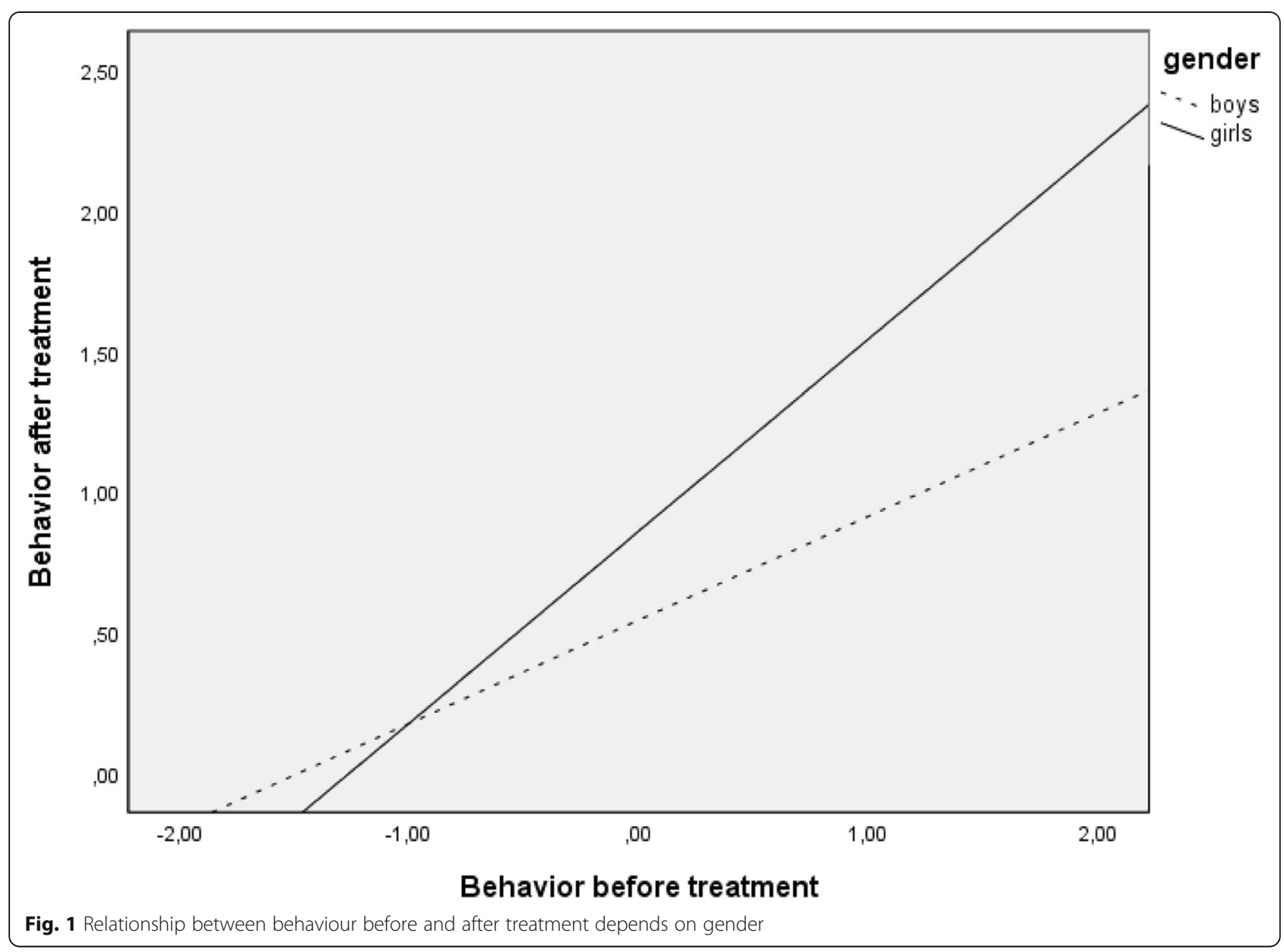




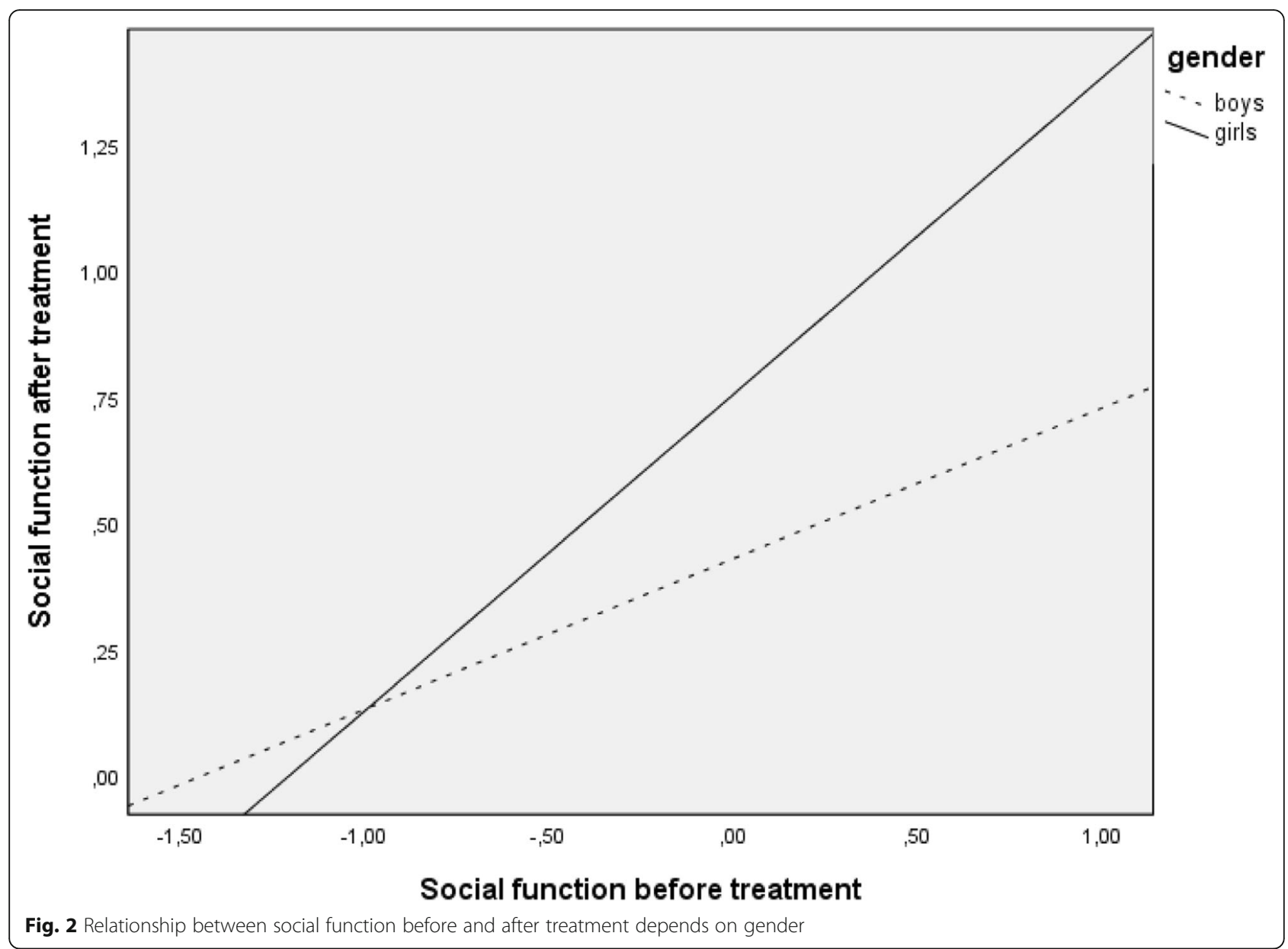

of measures used for the evaluation of QoL with regards to the instruments being not specific to children and adolescents with this condition.

Among the general QoL assessment instruments applied to $\mathrm{CL} / \mathrm{P}$, the Oral Health Impact Profile-14 (OHIP-14) should be highlighted owing to its high frequency of use. Thus, with this instrument, Beluci and Genaro [1] found QoL increases after treatment in the physical, psychological, and environmental domains (in line with our results), but reported no significant differences in social relationships before and after treatment. However, Antoun et al. [23], also using OHIP-14, reported a small change in OHRQoL pre-post treatment in a CL/P sample (in comparison with outcomes of surgical patients without a cleft). This small change is argued on the basis that cleft patients do not experience a drastic transformation of their appearance compared to other surgical patients. Broder et al. [2], using the Child Oral Health Impact Profile, found that surgical youth with a cleft experienced the greatest increase in OHRQoL in comparison with non-surgical youth with CL/P.

Other results using general QoL instruments (e.g. Michigan Oral Health-Related Quality of Life Scale) after treatment, in samples between 12 and 23 years of age, indicated adequate levels of QoL after treatment, particularly in the domain of oral functionality, consistent with our results [5].

As noted, other studies have used specific instruments to measure QoL in patients with $\mathrm{CL} / \mathrm{P}$. These include the questionnaire designed by Piombino et al. [24], whose adaptation we used in the present study. To our knowledge, this instrument is the only one that, administered only once, after the intervention, allows an assessment of the patient's perception, before and after treatment, of different domains of QoL. The results, in an age sample of 16 to 23 year olds, showed improvements in the physical health domain and in psychological health (specifically the behaviour dimension), although they did not make a differential analysis of the effect sizes on the perception of improvement in the different domains [24].

The differential study of the self-perception of QoL improvement after treatment is a novel aspect of this research. Our results show that this self-perception of improvement (assessed at a single moment in time through both a current and a retrospective perception) coincides, 
as a whole, with the results of improved QoL observed in studies with 'pre-post' treatment designs [1].

In this context, effective treatment is important, particularly surgery, as its effect is a possible improvement on self-perception [19]. Few studies have placed value on the improvement in the psychological and social health areas in relation to the physical area after treatment in children and adolescents. Moreover, the few results in this regard are not conclusive. Albers et al. [19], in a population with CL/P (aged 12 to 63 years), observed a reduction in dissatisfaction with facial appearance after nose surgery, but found no significant change in self-concept in the short term. They concluded that, after years of psychological adaptation to the malformation, relatively small changes from functional and cosmetic surgery can result in a significant reduction in distress and increased psychological well-being. However, other studies have predicted improvements in self-concept after treatment [18, 26]. Self-concept has been conceptualized as a central element in most studies, looking at improving OHRQoL in children with $\mathrm{CL} / \mathrm{P}$ after treatment [27].

Our results indicate significant 'pre-post' treatment improvements in all of the assessed QoL areas, from the young patients' retrospective perception. Consistent with previous studies, the highest effect sizes were observed in physical health, particularly in physical function and communication, as they involve the direct results of the intervention itself. The psychological (self-concept and behaviour) and social health domains showed moderate effect sizes. In this context, and given the absence of studies carried out from this pre-post retrospective design in children and adolescents, future research should be directed at the mechanisms of improvement in the psychological and social areas after treatment.

Finally, another aspect of interest in this study, which has been absent in previous ones, is the possible interaction of gender and age in pre-post treatment improvements across the different domains of QoL. Regarding the interaction of gender in these domains, no direct effects on QoL were found after treatment improvement; however, a gender interaction was observed in the relation between the domains before and after treatment, particularly in behaviour and social function. Specifically, perception of posttreatment QoL was more influenced by perception of previous QoL in girls than in boys. This finding has important practical repercussions, as the effects of treatment on QoL will depend on perception of previous QoL to a greater extent in girls than in boys. Thus, differential and personalized preventative treatment actions must be applied in different domains. To our knowledge, no previous studies have specifically addressed this issue. However, although unrelated to treatment, different authors [2, 3, 10, 27] have reported greater perception of aesthetic and behavioural problems, dissatisfaction with their image, low self-concept, and emotional instability in women than in men with $\mathrm{CL} / \mathrm{P}$, and particularly, in the young and adolescent population. The differences with regards to social function are controversial, with studies indicating better [28] and worse scores [10] for women than for men in this domain.

Regarding age, no interaction effects were observed in the relation between QoL perceptions before and after treatment. We only found that social functioning after treatment improved with the age of the children and adolescents. However, while some studies have pointed to a better psychosocial adjustment in older adolescents [3], others have found worse psychosocial adjustment at a later age $[23,29]$. These results could be explained by the disparity in the instruments and age ranges considered; in any case, none of the preceding studies have evaluated the influence of age on the relationship of QoL before and after treatment.

The present study has a number of limitations that need to be considered. The associations must be interpreted according to the observational nature of the study design, which does not allow inferences of causality. Although the advantage of the instrument used for the measurement of QoL, compared with the rest of the existing ones, lies in its assessment of variables before and after the treatment, it did so retrospectively, being administered at a single moment in time in our study. It is important to note that this assessment is not equivalent to the administration of the same instrument at two different times (before and after the intervention). In particular, the retrospective measure (especially the pretreatment moment) could lead to an overestimation bias of the current QoL compared with the previous one.

Furthermore, the instrument does not allow to assess which treatment (surgical and/or orthodontic) produces the perception of improvement. The age range considered was wide, although relatively narrow compared with other studies $[18,19]$. However, with regards to this limitation, our results indicated the absence of significant relations (except in the case of social function) between age and QoL. Finally, we should add the nonconsideration of the type of cleft, and therefore the type of malocclusion, as an analysis variable (owing to the size of the sample), which made it impossible to evaluate the results according to the severity of the malformation. Nonetheless, the dimensions of QoL contemplated are common to all types of clefts. Thus, we encourage researchers to replicate these findings using different populations with $\mathrm{CL} / \mathrm{P}$ and including other important variables such as clinical orthodontic outcomes. 


\section{Conclusion}

The present findings have important clinical implications. The study found relative improvements in the QoL of children and adolescents with CL/P after receiving treatment compared with their perception before treatment. The physical function domain showed the best results, which in turn may influence the positive effects on psychological and social health. We also found that improvements in QoL, in terms of behaviour and social function after treatment, could be influenced more by their respective levels (pre-treatment) in the case of girls. In this sense, personalized preventative measures from holistic and biopsychosocial approaches are necessary.

\section{Abbreviations}

QoL: Quality of life; CL/P: Cleft lip/palate; OHRoL: Oral health-related quality of life; QoLAdoCleft: Quality of life adolescents questionnaire; OHIP-14: Oral health impact profile-14

\section{Acknowledgements}

Our thanks to Dr. Piombino for providing us with the questionnaire used in this research.

\section{Authors' contributions}

CP: study design, statistical analysis, proofreading. CS: study design, statistical analysis. AR: collect samples, write up. MR: collect samples, proofreading. CG: proofreading. All authors read and approved the final manuscript.

\section{Funding}

This study did not receive any specific funding.

\section{Availability of data and materials}

The datasets used and/or analysed during the current study are available from the corresponding author on reasonable request.

\section{Declarations}

\section{Ethics approval and consent to participate}

Informed consent was obtained from all participant's parents included in the study. This project has been reviewed and accepted by the bioethics committee of the Rey Juan Carlos University. No. 110720166716.

\section{Consent for publication}

Not applicable.

\section{Competing interests}

The authors declare that they have no competing interests.

\section{Author details}

${ }^{1}$ Department of Nursing and Dentistry, Rey Juan Carlos University, Madrid, Spain. ${ }^{2}$ Pediatric Dentist, Private Practice, Madrid, Spain. ${ }^{3}$ Department of Basic and Clinical Psychology and Psychobiology, Jaume I University, Castellón, Spain. ${ }^{4}$ Orthodontic Department, Rey Juan Carlos University, Madrid, Spain. ${ }^{5}$ Department of Medical Specialties and Public Health, Rey Juan Carlos University, Madrid, Spain. ${ }^{6}$ Deparment of Psychology, Rey Juan Carlos University, Madrid, Spain.

Received: 15 October 2020 Accepted: 15 March 2021 Published online: 01 April 2021

\section{References}

1. Beluci ML, Genaro KF. Quality of life of individuals with cleft lip and palate pre- and post-surgical correction of dentofacial deformity. Rev da EsC Enferm. 2016;50(2):216-21. https://doi.org/10.1590/S0080-6234201600002 00006.
2. Broder $\mathrm{HL}$, Wilson-Genderson M, Sischo L. Oral health-related quality of life in youth receiving cleft-related surgery: self-report and proxy ratings. Qual Life Res. 2017;26(4):859-67. https://doi.org/10.1007/s11136-016-1420-5.

3. Pisula E, Lukowska E, Fudalej PS. Self-esteem, coping styles, and quality of life in Polish adolescents and young adults with unilateral cleft lip and palate. Cleft Palate Craniofacial J. 2014;51(3):290-9. https://doi.org/10.1597/13-002.

4. Menon A, Krishnan S, Shetty V. Development and application of a novel patient-reported outcome measure on QoL and facial aesthetics - a study on South Indian population. Cleft Palate Craniofacial J. 2019;56(10):1340-52. https://doi.org/10.1177/1055665619852571.

5. Munz SM, Edwards SP, Inglehart MR. Oral health-related quality of life, and satisfaction with treatment and treatment outcomes of adolescents/young adults with cleft lip/palate: An exploration. Int J Oral Maxillofac Surg. 2011; 40(8):790-6. https://doi.org/10.1016/j.jom.2011.03.002.

6. Arndt EM, Travis F, Lefebvre A, Niec A, Munro IR. Beauty and the eye of the beholder: social consequences and personal adjustments for facial patients. Br J Plast Surg. 1986;39(1):81-4. https://doi.org/10.1016/0007-122 6(86)90009-3.

7. Ward JA, Vig KWL, Firestone AR, Mercado A, Da Fonseca M, Johnston W. Oral health-related quality of life in children with orofacial clefts. Cleft Palate Craniofacial J. 2013:50(2):174-81. https://doi.org/10.1597/11-055.

8. Eckstein DA, Wu RL, Akinbiyi T, Silver L, Taub PJ. Measuring quality of life in cleft lip and palate patients: Currently available patient-reported outcomes measures. Plast Reconstr Surg. 2011;128(5):518-26. https://doi.org/10.1097/ PRS.0b013e31822b6a67.

9. Wehby G, Tyler M, Lindgren S, Romitti P, Robbins J, Damiano P. Oral clefts and behavioral health of young children. Oral Dis. 2012;18(1):74-84. https:// doi.org/10.1111/j.1601-0825.2011.01847.x.

10. Al-Namankany A, Alhubaishi A. Effects of cleft lip and palate on children's psychological health: A systematic review. J Taibah Univ Med Sci. 2018;13(4): 311-8. https://doi.org/10.1016/j.jtumed.2018.04.007.

11. Esenlik E, Gibson T, Kassam S, Sato Y, Garfinkle J, Figueroa AA, AlQatami F, Runyan C, Alperovich M, Golinko MS, Lee C, Chatzigianni A, Zafeiriadis AA, Santiago P, Hosseinian B, Kaygısız EU, Üçüncü N, Aslan BI, Uzuner FD, Gülşen A, Akkurt A, Arslan SG, Sabás M, Muñoz-Mendoza MA, Masis D, Holguin L, Granados A, Rojas NE, Campo B, Keskin K, Akçam MO, Lowe KM, Morselli PG, Pannuto L, Yarza IN, Martinez AT, Coşkun EY, Nissan S. NAM Therapy — Evidence-Based Results. Cleft Palate Craniofac J. 2020;57(4):529_ 31. https://doi.org/10.1177/1055665619899752.

12. Jodeh DS, Ruso S, Feldman R, Ruas E, Rottgers SA. Clinical Outcomes Utilizing a "Modified Latham " Appliance for Presurgical Infant Orthopedics in Patients With Unilateral Complete Cleft Lip and Palate. Cleft PalateCraniofacial J. 2019;56(7):929-35. https://doi.org/10.1177/1055665618816892.

13. Gatti GL, Freda N, Giacomina A, Montemagni M, Sisti A. Cleft Lip and Palate Repair : Our Experience. J Craniofac Surg. 2017;28(8):1918-24. https://doi. org/10.1097/SCS.0000000000003820.

14. Silva HPV, Arruda TTS, de Souza KSC, et al. Risk factors and comorbidities in Brazilian patients with orofacial clefts. Braz Oral Res. 2018;32:1-12.

15. Burg ML, Chai Y, Yao CA, lii WM, Figueiredo JC. Epidemiology, etiology, and treatment of isolated cleft palate. Front Physiol. 2016;7:67. https://doi.org/1 0.3389/fphys.2016.00067 Epidemiology, Etiology, and Treatment of Isolated Cleft Palate.

16. Allam E, Ghoneima A, Tholpady S, Kula K. Enamel Hypomineralization in Children With Clefts and the Relationship to Treatment A Cross-sectional Retrospective Study. Head Neck Surg. 2018;81(5):544-7. https://doi.org/10.1 097/SAP.0000000000001538.

17. Hameed O, Amin N, Haria P, Patel B, Hay N. Orthodontic burden of care for patients with a cleft lip and/or palate. J Orthod. 2019;46(1):63-7. https://doi. org/10.1177/1465312518823010.

18. Bemmels H, Biesecker B, Schmidt JL, Krokosky A, Guidotti R, Sutton EJ. Surgery among individuals with craniofacial conditions: an exploratory study. Cleft Palate Craniofac J. 2013;50(2):158-67. https://doi.org/10.1 597/11-127.Psychological.

19. Albers AE, Reichelt AC, Nolst-Trenité GJ, Menger DJ. Feeling normal? Longterm follow-up of patients with a cleft lip-palate after rhinoplasty with the Derriford Appearance Scale (DAS-59). Facial Plast Surg. 2016;32(2):219-24. https://doi.org/10.1055/s-0036-1579781.

20. Tannure PN, Soares FMM, Küchler EC, Motta LG, Costa MC, Granjeiro JM Measuring the impact of quality of life of children treated for orofacial clefts: a case-control study. J Clin Pediatr Dent. 2013;37(4):381-4. https://doi. org/10.17796/jcpd.37.4.f185423j04m66753. 
21. Wong Riff KWY, Tsangaris E, Forrest CR, et al. CLEFT-Q: Detecting differences in outcomes among 2434 patients with varying cleft types. Plast Reconstr Surg. 2019;144(1):78e-88e. https://doi.org/10.1097/PRS.0000000000005723.

22. Patjanasoontorn N, Pradubwong S, Mongkoltawornchai S, Phetcharat T, Chowchuen B. Development and reliability of the THAICLEFT quality of life questionnaire for children with Cleft Lip/Palate and families. J Med Assoc Thail. 2010;93(SUPPL 4):S16-8.

23. Antoun JS, Fowler PV, Jack HC, Farella M. Oral health-related quality of life changes in standard, cleft, and surgery patients after orthodontic treatment. Am J Orthod Dentofac Orthop. 2015;148(4):568-75. https://doi.org/10.1016/ j.ajodo.2015.03.028

24. Piombino P, Ruggiero F, Orabona GDA, et al. Development and validation of the quality-of-life adolescent cleft questionnaire in patients with cleft lip and palate. J Craniofac Surg. 2014;25(5):1757-61. https://doi.org/10.1097/ SCS.0000000000001033.

25. Hayes AF. Introduction to Mediation, Moderation, and Conditional Process Analysis. A Regression-Based Approach. (2nd Ed.).; 2017.

26. Roosenboom J, Hellings PW, Picavet VA, Prokopakis EP, Antonis Y, Schoenaers J, Poorten W, Claes P, Hens G. Secondary Cleft rhinoplasty: Impact on self-esteem and quality of life. Plast Reconstr Surg. 2014;134(6): 1285-92. https://doi.org/10.1097/PRS.0000000000000727.

27. Sischo L, Wilson-Genderson M, Broder HL. Quality-of-life in children with orofacial clefts and caregiver well-being. J Dent Res. 2017;96(13):1474-81. https://doi.org/10.1177/0022034517725707.

28. Ruff RR, Sischo L, Broder H. Resiliency and socioemotional functioning in youth receiving surgery for orofacial anomalies. Community Dent Oral Epidemiol. 2016;44(4):371-80. https://doi.org/10.1111/cdoe.12222.

29. Naros A, Brocks A, Kluba S, Reinert S, Krimmel M. Health-related quality of life in cleft lip and/or palate patients - a cross-sectional study from preschool age until adolescence. J Cranio-Maxillofacial Surg. 2018;46(10): 1758-63. https://doi.org/10.1016/j.jcms.2018.07.004.

\section{Publisher's Note}

Springer Nature remains neutral with regard to jurisdictional claims in published maps and institutional affiliations.

\section{Submit your manuscript to a SpringerOpen ${ }^{\circ}$ journal and benefit from:}

- Convenient online submission

- Rigorous peer review

- Open access: articles freely available online

High visibility within the field

- Retaining the copyright to your article

Submit your next manuscript at $\boldsymbol{\nabla}$ springeropen.com 